Research Article

\title{
The Influence of Marital Status on the Survival of Patients with Uveal Melanoma
}

\author{
Wenting Cai $\mathbb{D}^{1},{ }^{1}$ Jiaqi Fan $(\mathbb{D})^{2}$ Tianyi Shen $\mathbb{D}^{1},{ }^{1}$ and Jing Yu $\mathbb{D}^{1,3}$ \\ ${ }^{1}$ Department of Ophthalmology, Shanghai Tenth People's Hospital, Tongji University, School of Medicine, Shanghai, China \\ ${ }^{2}$ Department of Ophthalmology, Nanjing Medical University, Nanjing, China \\ ${ }^{3}$ Department of Ophthalmology, Ninghai First Hospital, Ninghai, Zhejiang, China
}

Correspondence should be addressed to Jing Yu; dryujing@aliyun.com

Wenting Cai and Jiaqi Fan contributed equally to this work.

Received 10 April 2020; Revised 26 August 2020; Accepted 12 November 2020; Published 4 December 2020

Academic Editor: Michele Figus

Copyright (C) 2020 Wenting Cai et al. This is an open access article distributed under the Creative Commons Attribution License, which permits unrestricted use, distribution, and reproduction in any medium, provided the original work is properly cited.

Background. Uveal melanoma (UM) is the most common primary intraocular tumor in adults and arises from the uvea. Marital status was a vital factor among physical conditions and social networks of cancer patients. Our study aimed to evaluate the impact of marital status on the outcomes among patients with UM. Methods. Patients with UM newly diagnosed from 2004 to 2015 were extracted, and the data were extracted from Surveillance, Epidemiology, and End Results (SEER) program. Overall survival (OS) was measured via the log-rank test, as well as cancer-specific survival (CSS) was also calculated via the same method. Cox proportional hazards models were applied to assess whether marital status was related to both OS and CSS. Furthermore, we performed subgroup analysis depending on different sexes and SEER stages. Results. In total, 4217 eligible patients were involved. Of these patients, $66.2 \%$ ( $n=2793)$ were married, $14.6 \%(n=615)$ were single, and 9.0\% $(n=379)$ were divorced or separated, as well as widowed were $10.2 \%$ $(n=430)$. The 5-year OS of married, single, divorced or separated, and widowed patients was $74.0 \%, 72.8 \%, 68.6 \%$, and $55.8 \%$, respectively. The results indicating better OS and CSS occurred among married patients. Other factors such as sex, age at diagnosis, and SEER stage were also correlated with survival in UM patients. Furthermore, subgroup analyses were consistent with the results above. Conclusion. Marital status was proved to be an independent prognostic value for survival in UM patients. In addition, contrast to married patients, widowed individuals showed poor OS and CSS at different subgroup analyses.

\section{Introduction}

Ocular melanoma is the most common form of primary cancer that influences ocular health [1]. Of these, uveal melanoma (UM) is the most common primary intraocular tumor in adults that arises from the uvea, including the iris, ciliary body, and choroid. The prevalence of UM diagnosed in the United States was 4.9 cases per million every year $[2,3]$. Of these cases, $85 \%$ originate from the choroidal body, and the remaining originate from the iris and ciliary body. The 5-year overall survival in patients with UM was $76.8 \%$, while the 5-year cancer-specific survival was $84.1 \%$ [4]. Previous studies reported that age, histologic type, surgery, and radiotherapy were correlated with prognosis [5]. Considering the prognostic factors associated with UM might provide new potential strategies for UM management and prevention.

Marital status, as a mediating marker of social family condition and mental status, is considered a vital factor that offers modified physical conditions and social networks among patients with a variety of cancers [6-10]. Xie et al. found marital status was closely related with astrocytoma patients, and more physiological support was recommended to patients with aborted marriage [11]. In patients with uterine cancer, the results indicated that poor outcomes were observed in widowed patients, while marriage contributed to a better prognosis, most likely due to spiritual and emotional support [12], yet there seems to be no study investigating the influence of marital status on UM patients. In general, we sought to investigate whether marital status 
could be a prognostic factor for UM and to explore suitable and timely supporting.

\section{Materials and Methods}

2.1. Data Source and Selection Criteria. SEER * Stat software, version 8.3.5, (National Cancer Institute, Bethesda, MD) was used to download primary data.

We extracted UM patients diagnosed between 2004 and 2015 to perform our further analysis. The data regarding sex, marital status, diagnosis year, age at diagnosis, race, SEER stage, histology type, AJCC stage, TNM stage, and treatment information about surgery, as well as median household income, were extracted. A total of 2413 patients were excluded (323 were under 18 years old, 582 were missing marital status information, 557 were missing SEER stage information, 607 were not at C69.3 or 69.4 labeled primary sites, and 344 were missing AJCC and TNM stage information). The patient selection criteria are shown in Figure 1.

2.2. Variables and Outcomes. Age was reported in ranges of $18-40,40-59,60-79$, and $\geq 80$ years, while race was categorized as black, white, others, or unknown using the SEER database. Marital status was categorized as married, single, divorced/separated, and widowed. Data related to diagnosis year (2004-2006, 2007-2009, 2010-2012, 2013-2015), SEER stage (localized, regional, metastatic), histology type (mixed epithelioid and spindle cell melanoma, malignant melanoma, NOS, spindle cell melanoma, others), AJCC stage (I, II, III, IV), and surgery were also obtained. Median household income was classified as $<\$ 4006$, $\$ 4006-\$ 4583$, $\$ 4583-\$ 5427$, or $\geq \$ 5427$. Registry sites included West (Alaska, California, Hawaii, New Mexico, Utah, Washington), Northeast (Connecticut, New Jersey), Midwest (Iowa, Michigan), and South (Georgia, Kentucky, Louisiana). Overall survival (OS) and cancer-specific survival (CSS) were set as primary end points.

2.3. Ethical Approval and Consent. Human participants in the present study were all subject to the ethical standards of the institutional research committee and also 1964 Helsinki Declaration as well as later amendments or comparable ethical standards. No animal studies were included in the present study.

2.4. Statistical Analysis. In our study, the relevant factors such as sex, diagnosed age and year, race, SEER stage, histology type, marital status, presence or absence of surgery, AJCC stage, median household income, as well as registry site. Data are presented as mean \pm SD. Categorical variables were recorded as counts (percentages). Continuous variables with symmetric distributions across subgroups of marital status were analyzed by variance. OS and CSS served as the primary outcomes.

The Kaplan-Meier method was plotted for assessing survival distributions. Chi-square tests were carried out to assess categorical variables between subgroups. Cox proportional hazards models were performed for assessing therapies for four marital statuses using hazard ratios (HRs) as well as $95 \%$ confidence intervals (CIs). SPSS Statistics, version 20 , was used to complete all statistical analyses. $P$ values lower than 0.05 were evaluated as statistically significant.

\section{Results}

3.1. Baseline Clinical Characteristics of UM Patients. In total, 4217 patients with UM were enrolled, including 2215 (52.5\%) male and 2002 (47.5\%) female individuals, and the median follow-up of all individuals was 45 months (range $0-143$ months). Of these individuals, $66.2 \%(n=2793)$ were married, $14.6 \%(n=615)$ were single, $9.0 \%(n=379)$ were divorced or separated, and $10.2 \%(n=430)$ were widowed. The 3-year OS in married, single, divorced or separated, and widowed individuals was $83.6 \%, 83.5 \%, 82.2 \%$, and $71.1 \%$, respectively. Furthermore, the 5-year OS of patients who were married, single, divorced or separated, and widowed was $74.0 \%, 72.8 \%, 68.6 \%$, and $55.8 \%$, respectively. As shown in Table 1, the detailed clinical characteristics of individuals categorized by different forms of marital status were listed.

The different forms of marital status was related to sex, diagnosis year, SEER historic stage, age at diagnosis, AJCC stage, presence or absence of surgery, median household income, and registry sites $(P<0.05)$. Notably, the percentage of widowed patients among the elderly ( $\geq 80$ years old) was the highest $(44.9 \%$ vs $3.7 \%-8.4 \%, P<0.001)$, while among those less than 40 years old, there tended to be a higher ratio of single patients than in the other three groups $(16.3 \%$ vs $0 \%-5.8 \%, P<.001)$. In addition, married patients were more probably to be male (59.1\%), and female individuals showed the highest percentage of widowhood $(77.4 \%$ vs $40.9 \%-$ $60.2 \%, P<0.001)$. The widowed group showed a higher prevalence in the SEER metastatic histologic stage than the married patients $(2.3 \%$ vs $1.0 \%, P<0.026)$.

3.2. Different Types of Marital Status Influenced OS and CSS on UM Patients. The results indicated males $(P=0.008)$, elderly $(P<0.001)$, black race $(P=0.001)$, widowed marital status $(P<0.001)$, as well as metastatic SEER stage $(P<0.001)$ were poor prognostic factors for OS among patients with UM in a univariate analysis. In Figures 2(a) and 2(b), lower OS and CSS occurred in widowed patients in contrast to other groups. Additionally, male and distance stage also showed disadvantages for survival (Figures 2(c)-2(f)). We further conducted multivariate Cox analyses. The results showed that female patients with UM had advantages in OS compared with male patients (HR: $0.770,95 \%$ CI: 0.682-0.870, $P<0.001)$. In contrast to the risk in married patients, higher risk of death was found in single individuals (HR: 1.203, 95\% CI: 1.005-1.440, $P=0.044$ ), divorced/separated group (HR: 1.305, 95\% CI: $1.065-1.600, P=0.010)$, and widowed group (HR: 1.300, 95\% CI: 1.086-1.556, $P=0.004$ ). Compared with the localized stage group, those in the regional and metastatic stage groups showed noticeably a higher risk of death (HR: 1.985, 95\% CI: 1.703-2.313, $P<0.001$; HR: 5.163, 95\% 


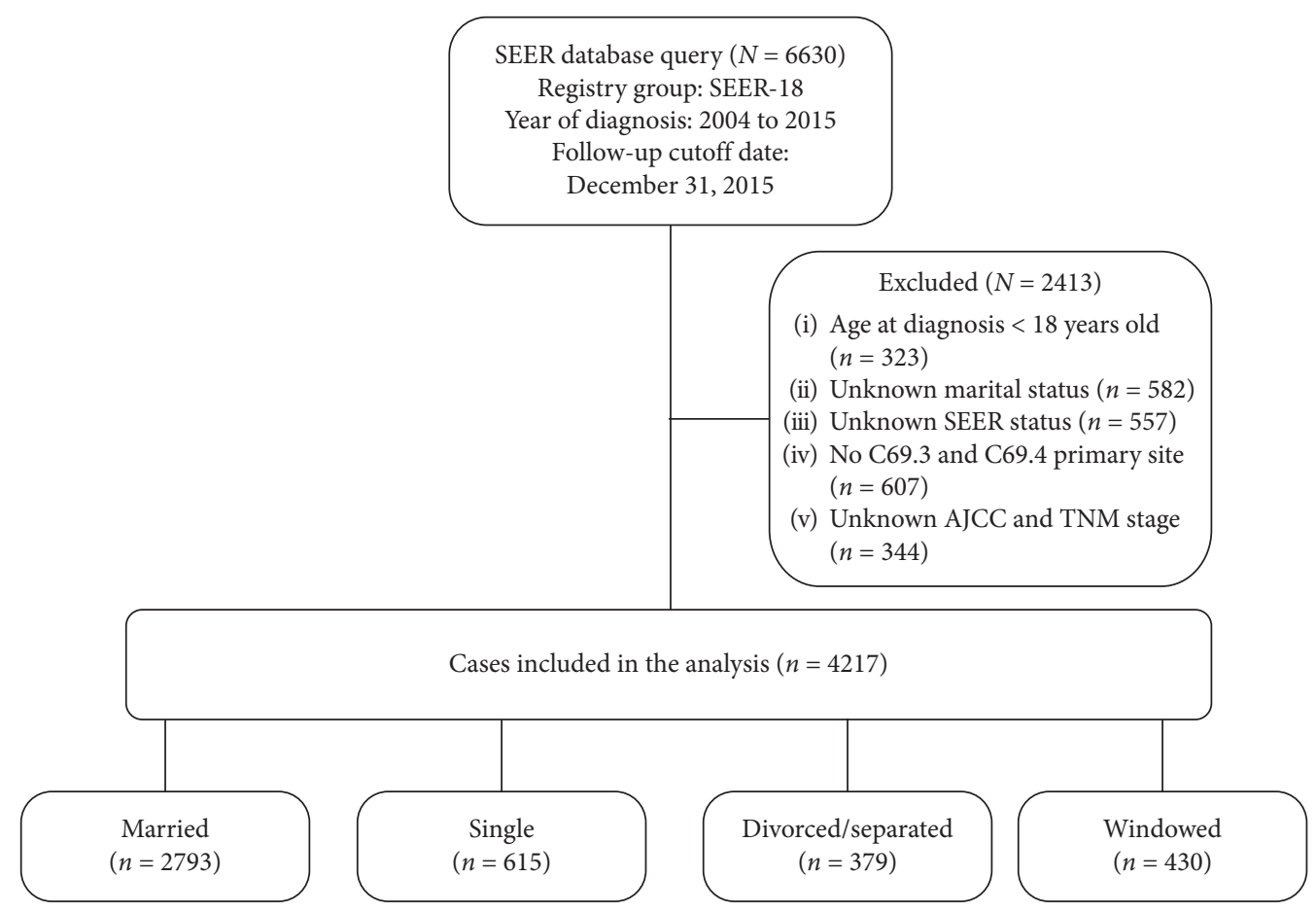

FIGURE 1: Flowchart describing the inclusion and exclusion of patients.

CI: 3.681-7.242, $P<0.001$, respectively) (Table 2 ). The Cox regression analysis of CCS also confirmed the results above. A high mortality rate was linked to patients in the metastatic stage group (HR: 10.733, 95\% CI: 6.351-18.141, $P<0.001$ ). Fewer cancer-related deaths were observed in female compared with male individuals (Table 3).

3.3. Subgroup Analyses Stratified by Sex to Investigate Relationship between Marital Status and Survival. We explored the impact of marital status on both OS and CCS, which was subgrouped by sex. The sex-specific survival curves of the OS and CCS of four marital statuses are presented in Figure 3. The results of the sex-specific Cox regression are summarized in Tables 4 and 5. In contrast to married patients, widowed patients had a worse prognosis regardless of whether the patients were male or female. The widowed patients had shorter median OS and CCS in the male group (OS: 37 vs 45 months, $P<0.001$; CSS: 37 vs 47 months, $P=0.002$ ) and female group (OS: 42 vs 48 months, $P<0.001$; CSS: 50 vs 51 months, $P=0.005)$ than others.

In a multivariate analysis, widowed individuals showed notably increased overall death not only in men (HR 2.350, 95\% CI 1.764-3.132, $P<0.001$ ) but also in women (HR 2.146, 95\% CI 1.749-2.633, $P<0.001)$ among four groups. Furthermore, the risk of cancer-specific death in widowed individuals also increased in contrast to married persons, both for males (HR 2.267, 95\% CI 1.226-4.193, $P<0.001$ ) and females (HR 1.721, 95\% CI 1.123-2.637, $P<0.001$ ).

3.4. Subgroup Analyses Stratified by SEER Stage to Observe the Impact of Marital Status on Survival. We then analyzed whether marital status showed any impact UM patients' prognosis, when subgrouped via three SEER stages. The curve and results are shown in Figure 4 and Tables 6 and 7. Compared with the widowed group, the married group had a longer median OS and CCS in the localized stage (OS: 46 vs 43 months, $P<0.001$; CSS: 49 vs 47.5 months, $P=0.002)$ and regional stage (OS: 54 vs 31 months, $P<0.001$; CSS: 66.5 vs 37 months, $P=0.01$ ) groups. No notable difference was observed between these two groups in the metastatic stage $(P>0.05)$.

In a multivariate analysis, widowed patients were observed with obviously increased risk of overall death in comparison with married individuals both in the localized stage (HR 1.953, 95\% CI 1.633-2.336, $P<0.001$ ) and regional stage (HR 2.161, 95\% CI 1.483-3.151, $P<0.001$ ) groups. Furthermore, the cancer-specific death in widowed patients was also increased compared with the risk in married patients, both in the localized stage (HR 1.598, 95\% CI 1.075-2.374, $P=0.02$ ) and regional stage (HR 2.077, 95\% CI 1.011-4.268, $P=0.047)$ groups. However, no notable difference was found in OS and CSS in the metastatic group $(P>0.05)$.

3.5. Subgroup Analyses Stratified by Age at Diagnosis to Study the Influence of Marital Status on Survival. We divided the UM patients into two groups based on whether over 60 years old. As shown in Figure 5 and Tables 8 and 9, married patients showed better OS and CCS in the older patient group (OS: $\chi^{2}=25.320, \quad P<0.001$; CCS: $\chi^{2}=10.296$, $P=0.016)$. In the multivariate analysis, patients were observed with notably an increased risk of overall death in comparison with married patients when they were over 60 years old (HR 1.516, 95\% CI 1.282-1.791, $P<0.001$ ). 
TABLE 1: Baseline characteristics of uveal melanoma patients in the SEER database eligible in this study.

\begin{tabular}{|c|c|c|c|c|c|c|}
\hline Characteristics & $\begin{array}{c}\text { Total (\%) } \\
4217(100)\end{array}$ & $\begin{array}{c}\text { Married (\%) } \\
2793(66.2)\end{array}$ & $\begin{array}{l}\text { Single (\%) } \\
615(14.6)\end{array}$ & $\begin{array}{c}\text { Divorced/separated (\%) } \\
379(9.0)\end{array}$ & $\begin{array}{c}\text { Widowed (\%) } \\
430(10.2)\end{array}$ & $P$ \\
\hline \multicolumn{7}{|l|}{ Gender } \\
\hline Male & $2215(52.5)$ & $1652(59.1)$ & $315(51.2)$ & $151(39.8)$ & $97(22.6)$ & \multirow[t]{2}{*}{$<0.001$} \\
\hline Female & $2002(47.5)$ & $1141(40.9)$ & $300(48.8)$ & $228(60.2)$ & $333(77.4)$ & \\
\hline \multicolumn{7}{|l|}{ Age at diagnosis } \\
\hline $18-40$ & $280(6.6)$ & $162(5.8)$ & $100(16.3)$ & $18(4.7)$ & $0(0.0)$ & \multirow{4}{*}{$<0.001$} \\
\hline $40-59$ & $1534(36.4)$ & $1077(38.6)$ & $266(43.3)$ & $162(42.7)$ & $29(6.7)$ & \\
\hline $60-79$ & $1922(45.6)$ & $1319(47.2)$ & $210(34.1)$ & $185(48.8)$ & $208(48.4)$ & \\
\hline$\geq 80$ & $481(11.4)$ & $235(8.4)$ & $39(6.3)$ & $14(3.7)$ & $193(44.9)$ & \\
\hline \multicolumn{7}{|l|}{ Race } \\
\hline Black & $28(0.7)$ & $16(0.6)$ & $6(1.0)$ & $3(0.8)$ & $3(0.7)$ & \multirow{4}{*}{0.907} \\
\hline White & $4071(96.5)$ & $2696(96.5)$ & $589(95.8)$ & $367(96.8)$ & $419(97.4)$ & \\
\hline Others & $62(1.5)$ & $42(1.5)$ & $11(1.8)$ & $4(1.1)$ & $5(1.2)$ & \\
\hline Unknown & $56(1.3)$ & $39(1.4)$ & $9(1.5)$ & $5(1.3)$ & $3(0.7)$ & \\
\hline \multicolumn{7}{|l|}{ Diagnosis year } \\
\hline $2004-2006$ & $1012(24.0)$ & $672(24.1)$ & $137(22.3)$ & $86(22.7)$ & $117(27.2)$ & \multirow{4}{*}{0.022} \\
\hline $2007-2009$ & $1034(24.5)$ & $688(24.6)$ & $133(21.6)$ & $92(24.3)$ & $121(28.1)$ & \\
\hline 2010-2012 & $1008(23.9)$ & $646(23.1)$ & $168(27.3)$ & $91(24.0)$ & $103(24.0)$ & \\
\hline $2013-2015$ & $1163(27.6)$ & $787(28.2)$ & $177(28.8)$ & $110(29.0)$ & $89(20.7)$ & \\
\hline \multicolumn{7}{|l|}{ SEER stage } \\
\hline Localized & $3767(89.3)$ & $2505(89.7)$ & $556(90.4)$ & $336(88.7)$ & $370(86.0)$ & \multirow{3}{*}{0.026} \\
\hline Regional & $399(9.5)$ & $260(9.3)$ & $55(8.9)$ & $34(9.0)$ & $50(11.6)$ & \\
\hline Metastatic & $51(1.2)$ & $28(1.0)$ & $4(0.7)$ & $9(2.4)$ & $10(2.3)$ & \\
\hline \multicolumn{7}{|l|}{ Histology type } \\
\hline Malignant melanoma, NOS & $3293(78.1)$ & $2196(78.6)$ & $460(74.8)$ & $301(79.4)$ & $336(78.1)$ & \multirow{4}{*}{0.423} \\
\hline Mixed epithelioid and spindle cell melanoma & $338(8.0)$ & $212(7.6)$ & $56(9.1)$ & $27(7.1)$ & $43(10.0)$ & \\
\hline Spindle cell melanoma & $428(10.1)$ & $285(10.2)$ & $71(11.5)$ & $36(9.5)$ & $36(8.4)$ & \\
\hline Others & $158(3.7)$ & $100(3.6)$ & $28(4.6)$ & $15(4.0)$ & $15(3.5)$ & \\
\hline \multicolumn{7}{|l|}{ AJCC stage } \\
\hline I & $1576(37.4)$ & $1054(37.7)$ & $231(37.6)$ & $146(38.5)$ & $145(33.7)$ & \multirow{4}{*}{0.037} \\
\hline II & $1803(42.8)$ & $1217(43,6)$ & $243(39.5)$ & $154(40.6)$ & $189(44.0)$ & \\
\hline III & $791(18.8)$ & $495(17.7)$ & $137(22.3)$ & $71(18.7)$ & $88(20.5)$ & \\
\hline IV & $47(1.1)$ & $27(1.0)$ & $4(0.7)$ & $8(2.1)$ & $8(1.9)$ & \\
\hline \multicolumn{7}{|l|}{ Surgery } \\
\hline Yes & $1232(29.2)$ & $757(27.1)$ & $212(34.5)$ & $128(33.8)$ & $135(31.4)$ & \multirow[t]{2}{*}{$<0.001$} \\
\hline No/unknown & $2985(70.8)$ & $2036(72.9)$ & $403(65.5)$ & $251(66.2)$ & $295(68.6)$ & \\
\hline \multicolumn{7}{|l|}{ Median household income } \\
\hline Quartile 1 & $1044(24.8)$ & $700(25.1)$ & $112(18.2)$ & $110(29.0)$ & $122(28.4)$ & \multirow{4}{*}{0.002} \\
\hline Quartile 2 & $1057(25.1)$ & $680(24.3)$ & $183(29.8)$ & $88(23.2)$ & $106(24.7)$ & \\
\hline Quartile 3 & $1060(25.1)$ & $720(25.8)$ & $155(25.2)$ & $90(23.7)$ & $95(22.1)$ & \\
\hline Quartile 4 & $1056(25.0)$ & $693(24.8)$ & $165(26.8)$ & $91(24.0)$ & $107(24.9)$ & \\
\hline \multicolumn{7}{|l|}{ Registry sites } \\
\hline West & $2322(55.1)$ & $1534(54.9)$ & $383(62.3)$ & $202(53.3)$ & $203(47.2)$ & \multirow{4}{*}{$<0.001$} \\
\hline Midwest & $508(12.0)$ & $333(11.9)$ & $63(10.2)$ & $46(12.1)$ & $66(15.3)$ & \\
\hline South & $802(19.0)$ & 548 (19.6) & $78(12.7)$ & $85(22.4)$ & $91(21.2)$ & \\
\hline Northeast & $585(13.9)$ & $378(13.5)$ & $91(14.8)$ & $46(12.1)$ & $70(16.3)$ & \\
\hline
\end{tabular}

Furthermore, the cancer-specific death in widowed patients was also increased compared with the risk in married patients. In addition, no obvious difference was observed in OS and CSS in patients under 60 years old $(P>0.05)$.

\section{Discussion}

Although the influence of marriage on cancer survival has been investigated in some studies [13-17], no study has emphasized the influence of marital status on UM patients or has conducted subgroup analysis stratified by sex and SEER stage. Here, we sought to investigate the correlations between the marital status and survival outcome in UM patients, who were diagnosed from 2004 to 2015. The results found married patients showed better prognosis than other three groups including single, divorced/separated, and widowed individuals. In particular, widowed individuals, due to some factors, showed lower survival than others.

In present study, the analysis indicated that male sex, elderly age, widowed status, and metastatic histologic stage were closely correlated with the prognosis of UM patients. Subgroup analysis was stratified according to sex, SEER stage, and age. Interestingly, we illuminated the highest 


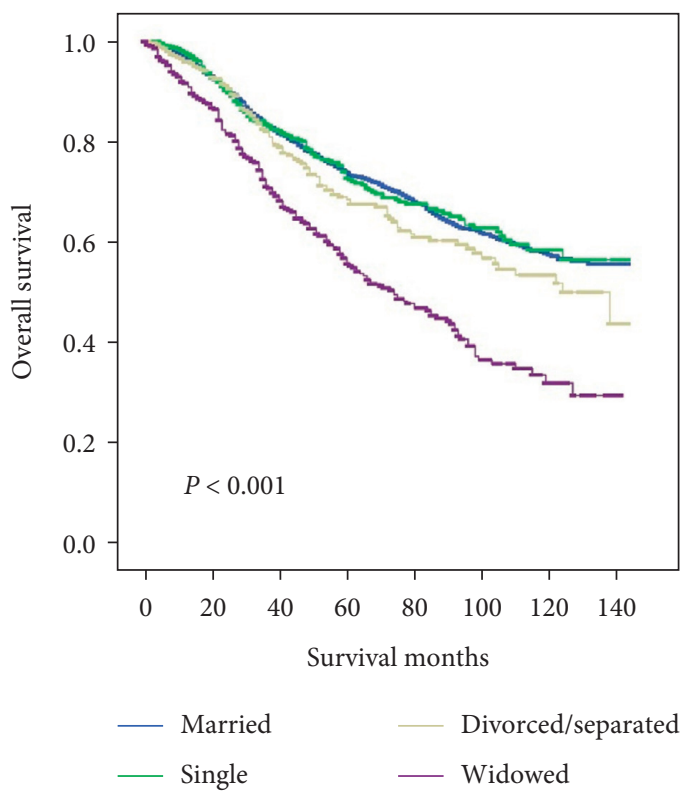

(a)

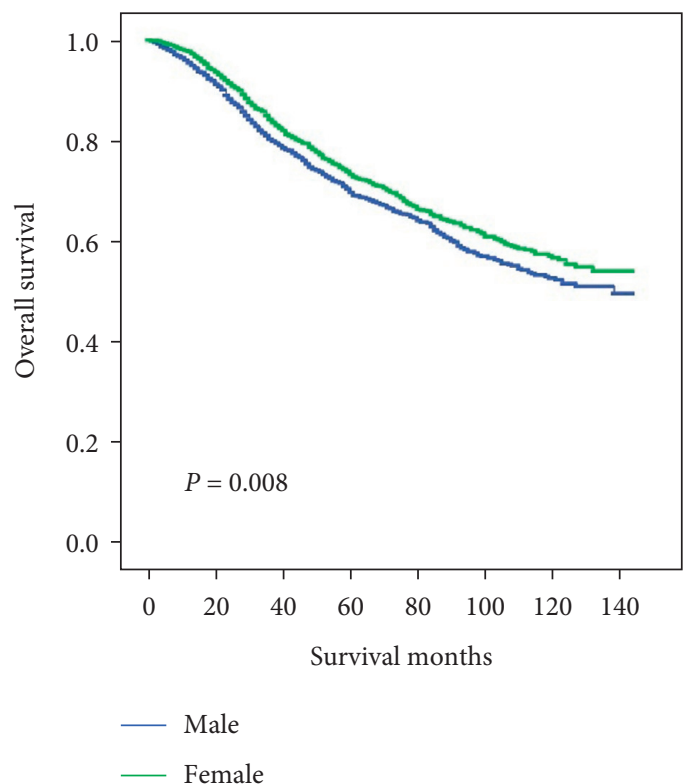

(c)

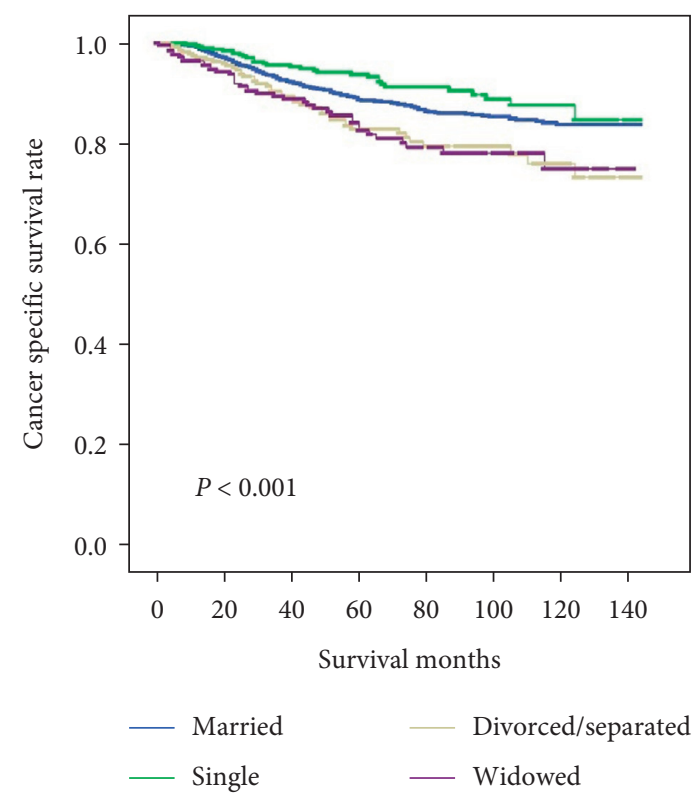

(b)

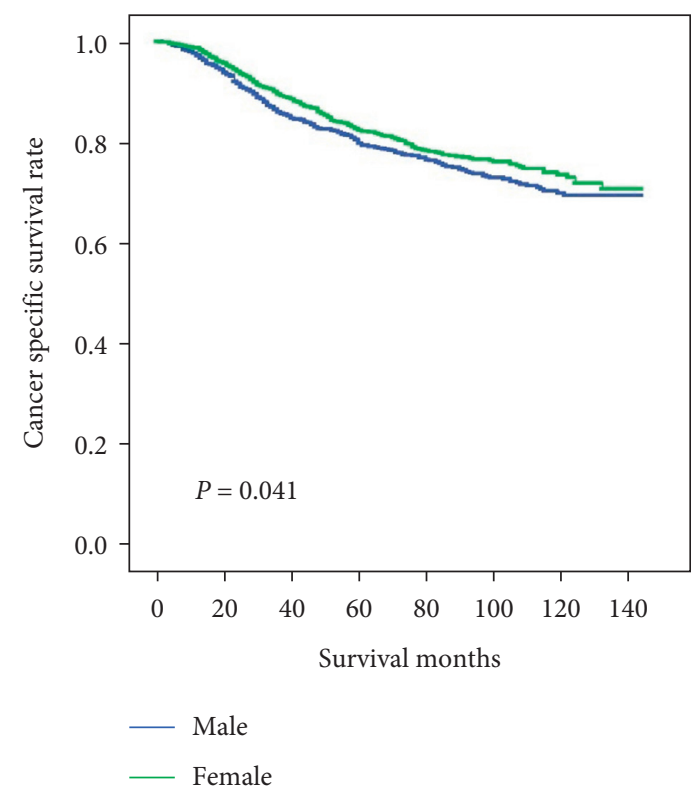

(d)

Figure 2: Continued. 


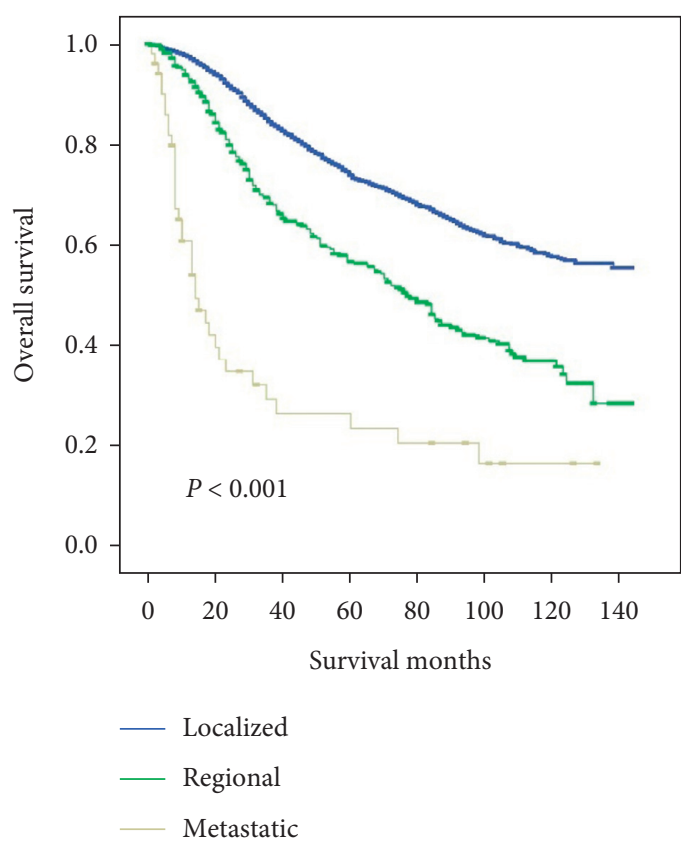

(e)

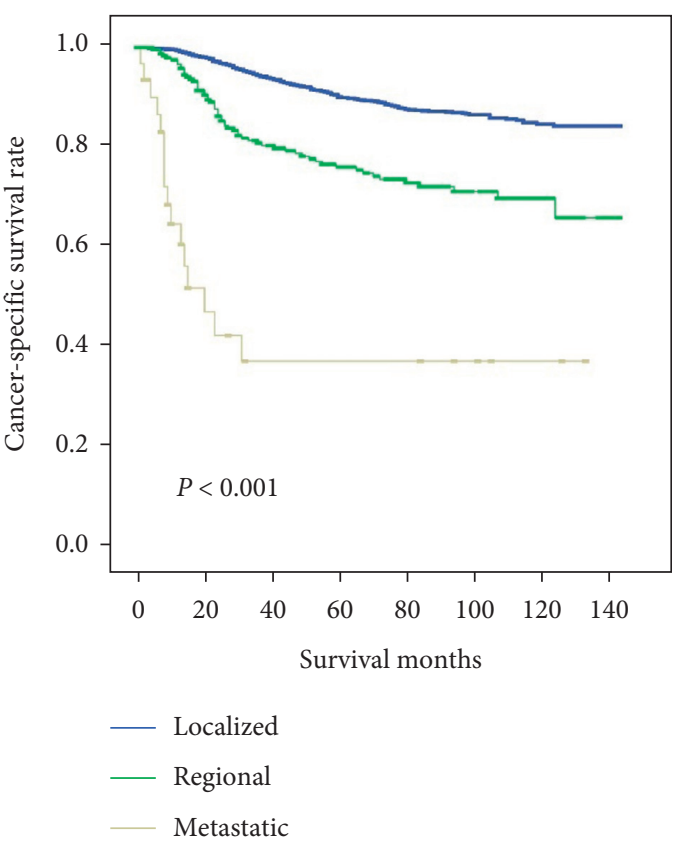

(f)

FIGURE 2: Kaplan-Meier comparison of overall survival (OS) and cancer-specific survival (CSS) (a, b) among patients with married, single, divorced or separated, and widowed status, $(c, d)$ among patients with different genders, and $(e, f)$ among patients stratified by SEER stage.

mortality rate occurred in widowed individuals not only for male patients but also for females, which was consistent with the aforementioned results. Further subgroup analysis stratified according to the SEER stage demonstrated that married patients in the localized and regional stage groups showed a higher survival rate than widowed patients. There was no significant difference for patients in the metastatic stage group, which might be due to the limited patient numbers in this group. What's more, the results showed the effect of marital status on both OS and CSS in patients over 60 years old. The probable reason why no obvious impact was observed in younger ones was that younger patients could get more support from friends, parents, or other sources, whereas older individuals lived with their spouse mostly.

Research on the impact of psychosocial well-being on survival has yielded various potential mechanisms to explain the relationship between marital status and survival. At first, patients suffer not only physical soreness but also psychological depression. Psychological depression and stress would lead to several dysfunctions, such as hypothalamicpituitary-adrenal (HPA) axis impairment and activation of inflammatory cytokines [18-20]. The impaired HPA axis results in glucocorticoid resistance and increased catecholamines [21]. Cytokines, including interleukin-6 (IL-6) as well as tumor necrosis factor- $\alpha$ (TNF- $\alpha$ ), mediate interactions with glucocorticoid signaling [22-24]. The disturbance of the HPA axis promotes tumor growth, invasion, and metastasis [25]. Second, unmarried patients, particularly widowed, seemed more probable to live following chronic psychological depression after diagnosis of cancer. In addition, unhealthy lifestyle habits, such as smoking, alcohol, or drug abuse, resulted in poor therapeutic outcomes [26].

The married patients had fewer complications and timelier follow-ups than the other patients during the course of treatment. Some studies reported that the complications noted at follow-up were fewer and that the treatment of married patients was better than those in the other groups. The spouse's support played crucial role in prognosis, due to their encouragement on keeping monitoring and treatment $[14,27]$. Magrin et al. conducted a meta-analysis and indicated that mental support from spouses encouraged patients to have better persistence and tolerance with therapy as well as regular follow-up [28]. Moreover, because access to high-quality healthcare is strongly linked to financial status, economic support from the spouse has advantages in terms of improving access to better therapeutic strategies and medications $[29,30]$. A recent study found that the differences in economic resources influenced the survival outcomes of cancer patients [29]. Finally, psychosocial and financial support from the spouse may decrease depression and enhance confidence in a patient's ability to triumph over illness $[31,32]$. Our analyses were consistent with previously reported studies. Therefore, we suggest that more psychological care and social support could be encouraged to patients as much as possible.

Psychological screening and intervention in the treatment of patients with UM have been recommended [33]. Williamson et al. conducted a 3 -month prospective study to investigate the supportive care needed for patients with cancer. The results suggested that effective 
TABLE 2: Univariate and multivariate analysis for OS in uveal melanoma patients.

\begin{tabular}{|c|c|c|c|c|c|}
\hline \multirow{2}{*}{ Variables } & \multirow{2}{*}{ Median OS (month) } & \multicolumn{2}{|c|}{ Univariate analysis } & \multicolumn{2}{|c|}{ Multivariate analysis } \\
\hline & & Log-rank $\chi^{2}$ & $P$ value & HR (95\% CI) & $P$ value \\
\hline Gender & & & & & $<0.001$ \\
\hline Male & 44 & 7.138 & 0.008 & Reference & \\
\hline Female & 47 & & & $0.770(0.682,0.870)$ & \\
\hline Age at diagnosis & & 77.138 & $<0.001$ & & $<0.001$ \\
\hline$<40$ & 51.5 & & & Reference & \\
\hline $40-59$ & 54 & & & $1.774(1.208,2.604)$ & 0.003 \\
\hline $60-79$ & 43 & & & $3.136(2.150,4.575)$ & $<0.001$ \\
\hline$\geq 80$ & 34 & & & $7.065(4.762,10.482)$ & $<0.001$ \\
\hline Race & & 16.063 & 0.001 & & 0.001 \\
\hline Black & 39 & & & Reference & \\
\hline White & 45 & & & $2.307(0.742,7.178)$ & 0.149 \\
\hline Others & 43.5 & & & $2.321(0.670,8.042)$ & 0.184 \\
\hline Unknown & 74 & & & $0.561(0.125,2.514)$ & 0.450 \\
\hline Diagnosis year & & 3.783 & 0.286 & & 0.058 \\
\hline 2004-2006 & 109 & & & & \\
\hline $2007-2009$ & 80 & & & & 0.025 \\
\hline 2010-2012 & 46 & & & & 0.023 \\
\hline 2013-2015 & 15 & & & & 0.856 \\
\hline Marital status & & 77.138 & $<0.001$ & & 0.003 \\
\hline Married & 46 & & & Reference & \\
\hline Single & 44 & & & $1.203(1.005,1.440)$ & 0.044 \\
\hline Divorced/separated & 43 & & & $1.305(1.065,1.600)$ & 0.010 \\
\hline Widowed & 41 & & & $1.300(1.086,1.556)$ & 0.004 \\
\hline SEER stage & & 213.756 & $<0.001$ & & $<0.001$ \\
\hline Localized & 45 & & & Reference & \\
\hline Regional & 50 & & & $1.985(1.703,2.313)$ & $<0.001$ \\
\hline Metastatic & 13 & & & $5.163(3.681,7.242)$ & $<0.001$ \\
\hline Surgery & & 81.276 & $<0.001$ & & $<0.001$ \\
\hline Yes & 38 & & & Reference & \\
\hline No/unknown & 47 & & & $0.588(0.523,0.661)$ & $<0.001$ \\
\hline Median household income & & 9.447 & 0.024 & & 0.145 \\
\hline Quartile 1 & 45 & & & & \\
\hline Quartile 2 & 42 & & & & 0.076 \\
\hline Quartile 3 & 44.5 & & & & 0.970 \\
\hline Quartile 4 & 49 & & & & 0.046 \\
\hline Registry sites & & 4.391 & 0.222 & & 0.015 \\
\hline West & 43 & & & Reference & \\
\hline Midwest & 46.5 & & & $0.861(0.715,1.036)$ & 0.113 \\
\hline South & 46 & & & $1.056(0.904,1.234)$ & 0.492 \\
\hline Northeast & 54 & & & $0.796(0.669,0.947)$ & 0.010 \\
\hline
\end{tabular}

psychoeducational interventions can be tailored to patients to reduce anxiety as well as address psychological needs and support [33-35]. Therefore, effective and timely psychological care has a beneficial impact on the development of these diseases.

Rajeshuni et al. made evaluation of socioeconomic associations with treatment and survival in UM. The results showed that socioeconomically disadvantaged patients with UM are more likely to be treated with primary enucleation and also revealed opportunities to address issues regarding treatment choice in UM, which was a merit point in this work [36]. However, no study has emphasized the influence of marital status on UM patients or has conducted subgroup analysis stratified by sex and SEER stage. In our present study, we emphasized these points, which was also an merit point in our work.
Although the data we extracted contained multiple UM patients in the United States, there are still some potential limitations in our study that we should consider. First, marital status here was the status when patients were diagnosed. Because the change of marital status after diagnosis was unknown, we cannot investigate the physical and mental care from the spouse on the patient's psychological health. Data on the alterative marital status of cancer patients were not available. Second, the 2010 US Census database indicated that only one-third of unmarried Americans who lived alone were without partners, and the others lived with partners even though their marital status was single [14]. These patients may also enjoy psychosocial and financial support from their partners, which would influence the reliability of our analysis to some extent. Third, this database mainly recorded US population, which could not by totally 
TABLE 3: Univariate and multivariate analysis for CSS in uveal melanoma patients.

\begin{tabular}{|c|c|c|c|c|c|}
\hline \multirow{2}{*}{ Variables } & \multirow{2}{*}{ Median CCS (month) } & \multicolumn{2}{|c|}{ Univariate analysis } & \multicolumn{2}{|c|}{ Multivariate analysis } \\
\hline & & Log-rank $\chi^{2}$ & $P$ value & HR (95\% CI) & $P$ value \\
\hline Gender & & & & & 0.023 \\
\hline Male & 47 & 4.164 & 0.041 & Reference & \\
\hline Female & 50 & & & $0.767(0.610,0.965)$ & \\
\hline Age at diagnosis & & 21.099 & $<0.001$ & & $<0.001$ \\
\hline$<40$ & 51.5 & & & Reference & \\
\hline $40-59$ & 57 & & & $1.221(0.680,2.190)$ & 0.504 \\
\hline $60-79$ & 46 & & & $2.329(1.316,4.124)$ & 0.004 \\
\hline$\geq 80$ & 33.5 & & & $3.730(1.931,7.205)$ & $<0.001$ \\
\hline Race & & 7.202 & 0.066 & & 0.158 \\
\hline Black & 34 & & & Reference & \\
\hline White & 48 & & & - & 0.055 \\
\hline Others & 44.5 & & & - & 0.673 \\
\hline Unknown & 77.5 & & & - & 0.031 \\
\hline Diagnosis year & & 17.289 & 0.001 & & 0.001 \\
\hline 2004-2006 & 117 & & & Reference & \\
\hline 2007-2009 & 86 & & & $0.588(0.448,0.773)$ & 0 \\
\hline $2010-2012$ & 48 & & & $0.707(0.522,0.956)$ & 0.025 \\
\hline 2013-2015 & 15 & & & $0.527(0.324,0.859)$ & 0.01 \\
\hline Marital status & & 21.099 & $<0.001$ & & 0.029 \\
\hline Married & 49 & & & Reference & \\
\hline Single & 47 & & & $0.851(0.580,1.247)$ & 0.407 \\
\hline Divorced/separated & 46 & & & $1.592(1.139,2.224)$ & 0.006 \\
\hline Widowed & 47 & & & $1.254(0.865,1.818)$ & 0.233 \\
\hline SEER stage & & 195.694 & $<0.001$ & & $<0.001$ \\
\hline Localized & 48 & & & Reference & \\
\hline Regional & 65.5 & & & $2.651(1.989,3.533)$ & $<0.001$ \\
\hline Metastatic & 13 & & & $10.733(6.351,18.141)$ & $<0.001$ \\
\hline Surgery & & 98.593 & $<0.001$ & & $<0.001$ \\
\hline Yes & 41 & & & Reference & \\
\hline No/unknown & 48 & & & $0.456(0.388,0.534)$ & $<0.001$ \\
\hline Median household income & & 10.754 & 0.013 & & 0.320 \\
\hline Quartile 1 & 47 & & & Reference & \\
\hline Quartile 2 & 45 & & & - & 0.413 \\
\hline Quartile 3 & 47 & & & - & 0.453 \\
\hline Quartile 4 & 55 & & & - & 0.853 \\
\hline Registry sites & & 10.613 & 0.014 & & 0.002 \\
\hline West & 46 & & & Reference & \\
\hline Midwest & 50 & & & $0.927(0.639,1.347)$ & 0.692 \\
\hline South & 48 & & & $1.620(1.242,2.113)$ & $<0.001$ \\
\hline Northeast & 60 & & & $0.923(0.667,1.278)$ & 0.631 \\
\hline
\end{tabular}

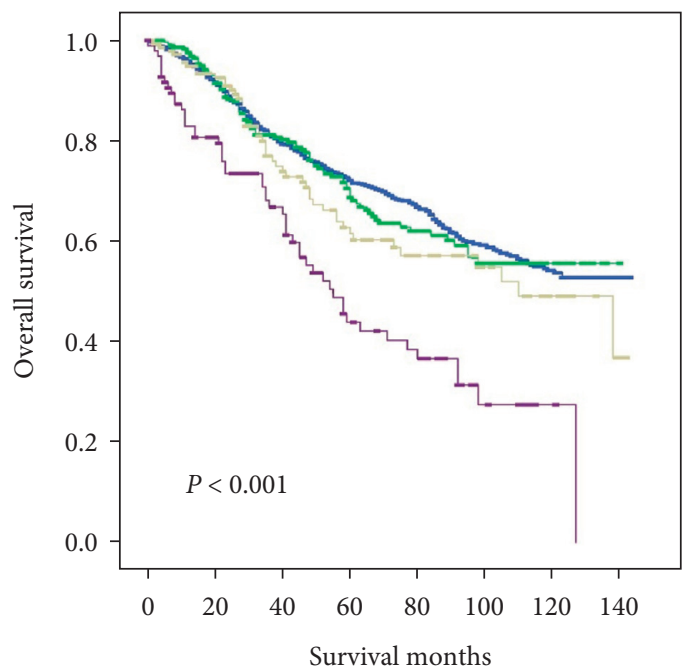

$\begin{array}{ll}\text { Married } & \text { Divorced/separated } \\ \text { Single } & \text { Widowed }\end{array}$

(a)

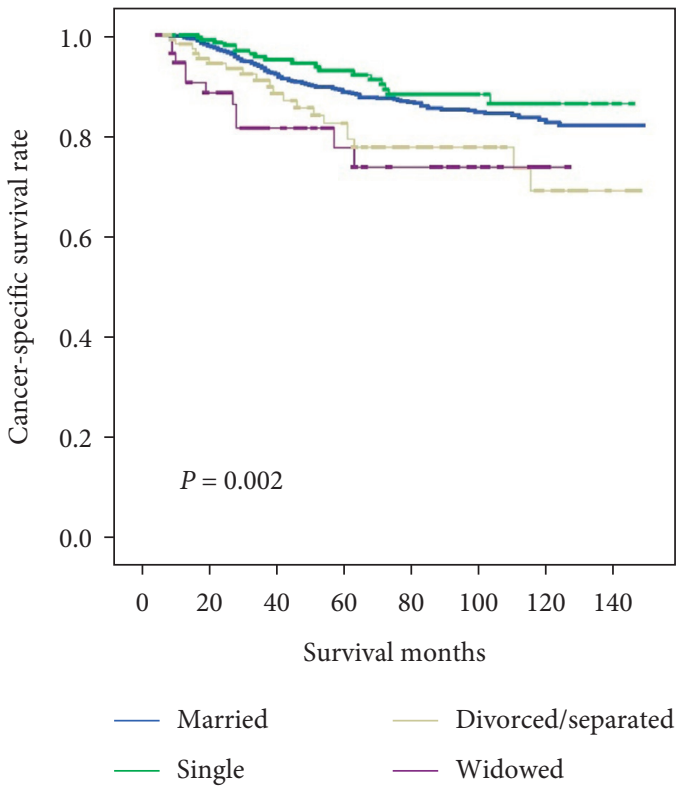

(b)

Figure 3: Continued. 


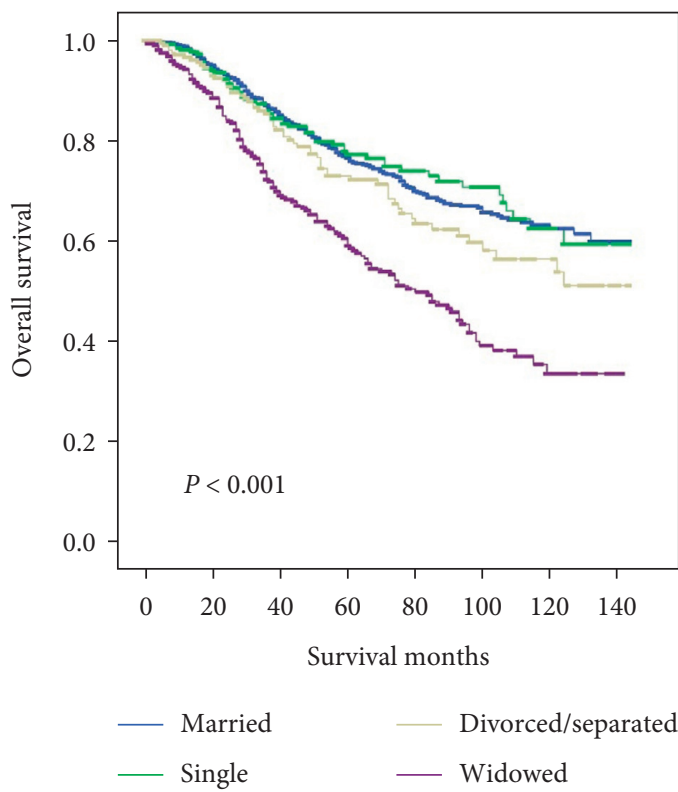

(c)

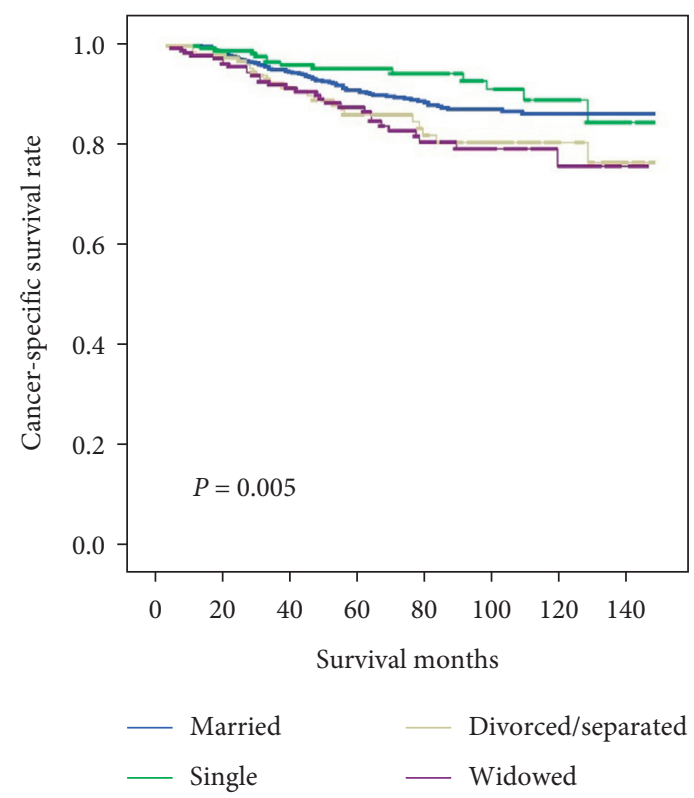

(d)

FIgURE 3: Kaplan-Meier comparison of OS and CSS among patients stratified by gender. (a, b) Male patients and (c, d) female patients.

TABLE 4: Univariate and multivariate analysis for evaluating the influence of marital status on OS according to gender.

\begin{tabular}{|c|c|c|c|c|c|}
\hline \multirow{2}{*}{ Variables } & \multirow{2}{*}{ Median OS (month) } & \multicolumn{2}{|c|}{ Univariate analysis } & \multicolumn{2}{|c|}{ Multivariate analysis } \\
\hline & & Log-rank $\chi^{2}$ & $P$ value & HR (95\% CI) & $P$ value \\
\hline Male & 44 & 37.102 & $<0.001$ & & $<0.001$ \\
\hline Married & 45 & & & Reference & \\
\hline Single & 44 & & & $1.053(0.837,1.325)$ & 0.658 \\
\hline Divorced/separated & 36 & & & $1.242(0.922,1.672)$ & 0.154 \\
\hline Widowed & 37 & & & $2.350(1.764,3.132)$ & $<0.001$ \\
\hline Female & 47 & 61.563 & $<0.001$ & & $<0.001$ \\
\hline Married & 48 & & & Reference & \\
\hline Single & 44 & & & $0.968(0.732,1.280)$ & 0.819 \\
\hline Divorced/separated & 46.5 & & & $1.265(0.959,1.670)$ & 0.097 \\
\hline Widowed & 42 & & & $2.146(1.749,2.633)$ & $<0.001$ \\
\hline
\end{tabular}

TABLE 5: Univariate and multivariate analysis for evaluating the influence of marital status on CCS according to gender.

\begin{tabular}{|c|c|c|c|c|c|}
\hline \multirow{2}{*}{ Variables } & \multirow{2}{*}{ Median CSS (month) } & \multicolumn{2}{|c|}{ Univariate analysis } & \multicolumn{2}{|c|}{ Multivariate analysis } \\
\hline & & Log-rank $\chi^{2}$ & $P$ value & HR (95\% CI) & $P$ value \\
\hline Male & 47 & 14.684 & 0.002 & & 0.006 \\
\hline Married & 47 & & & Reference & \\
\hline Single & 48 & & & $0.740(0.452,1.210)$ & 0.230 \\
\hline Divorced/separated & 40 & & & $1.741(1.089,2.785)$ & 0.021 \\
\hline Widowed & 37 & & & $2.267(1.226,4.193)$ & 0.009 \\
\hline Female & 50 & 12.744 & 0.005 & & 0.007 \\
\hline Married & 51 & & & Reference & \\
\hline Single & 47 & & & $0.675(0.375,1.214)$ & 0.189 \\
\hline Divorced/separated & 49 & & & $1.586(0.995,2.527)$ & 0.052 \\
\hline Widowed & 50 & & & $1.721(1.123,2.637)$ & 0.013 \\
\hline
\end{tabular}




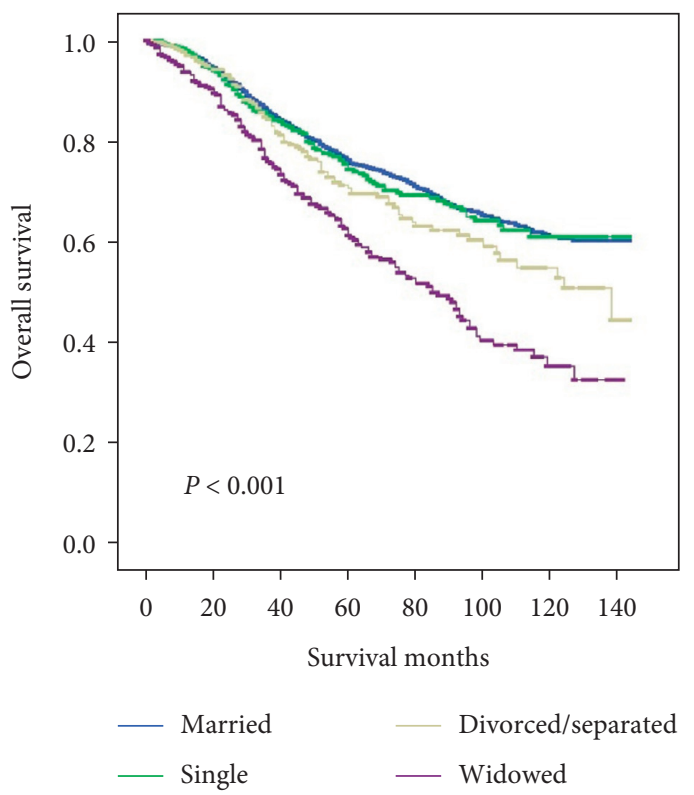

(a)

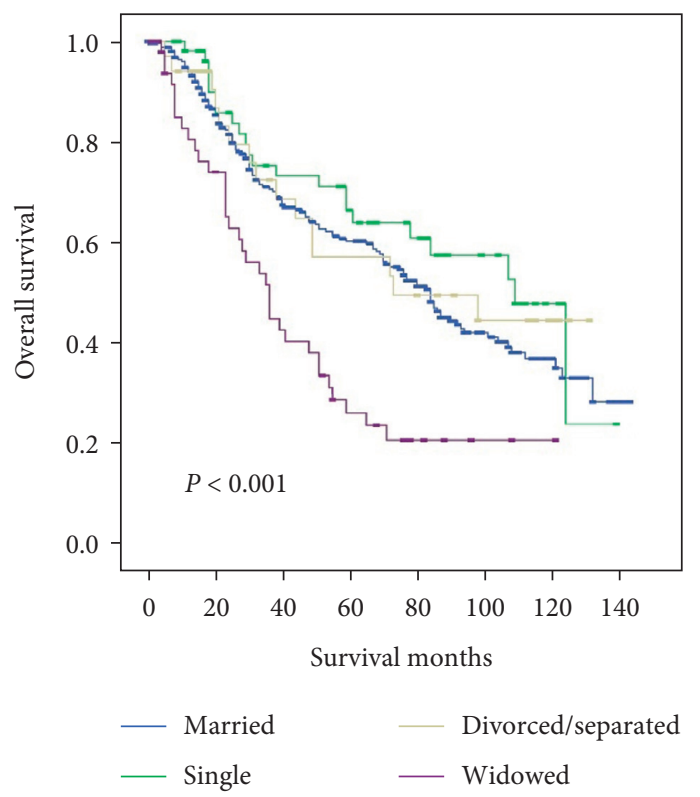

(c)

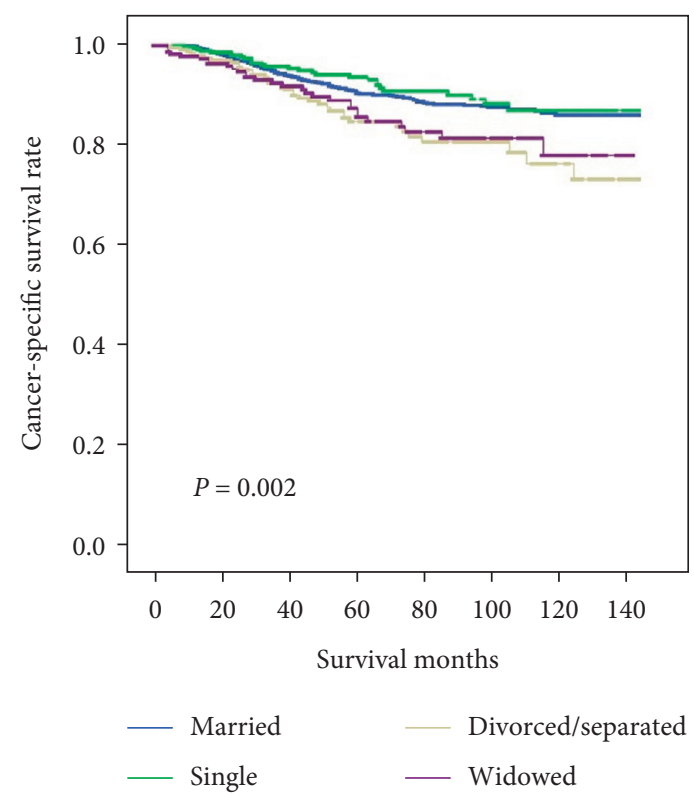

(b)

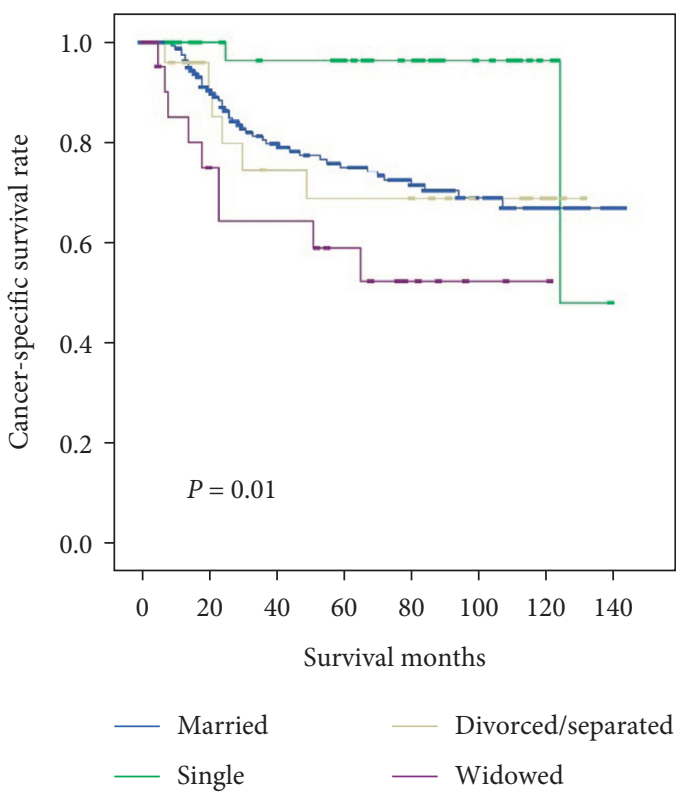

(d)

FIgURE 4: Continued. 


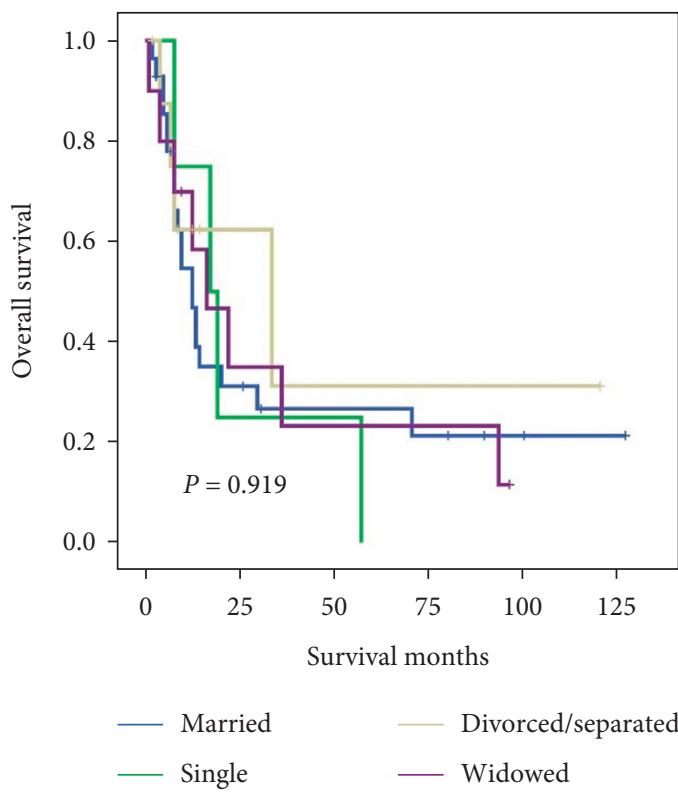

(e)

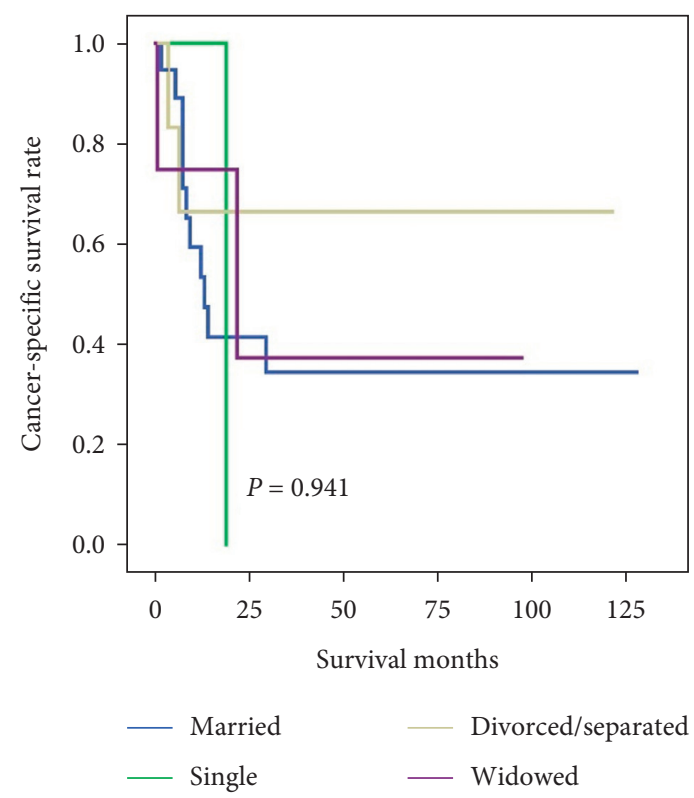

(f)

FIGURE 4: Kaplan-Meier comparison of OS and CSS among patients stratified by SEER stage. (a, b) Patients in the localized stage; (c, d) patients in the regional stage; $(e, f)$ patients in the distant stage.

TABLE 6: Univariate and multivariate analysis for evaluating the influence of marital status on OS according to SEER stage.

\begin{tabular}{|c|c|c|c|c|c|}
\hline \multirow{2}{*}{ Variables } & \multirow{2}{*}{ Median CSS (month) } & \multicolumn{2}{|c|}{ Univariate analysis } & \multicolumn{2}{|c|}{ Multivariate analysis } \\
\hline & & Log-rank $\chi 2$ & $P$ value & $\mathrm{HR}(95 \% \mathrm{CI})$ & $P$ value \\
\hline Localized & & 15.140 & 0.002 & & 0.004 \\
\hline Married & 49 & & & Reference & \\
\hline Single & 45 & & & $0.848(0.567,1.268)$ & 0.422 \\
\hline Divorced/separated & 46 & & & $1.744(1.210,2.516)$ & 0.003 \\
\hline Widowed & 47.5 & & & $1.598(1.075,2.374)$ & 0.020 \\
\hline Regional & & 11.432 & 0.010 & & 0.006 \\
\hline Married & 66.5 & & & Reference & \\
\hline Single & 77 & & & $0.209(0.051,0.861)$ & 0.030 \\
\hline Divorced/separated & 49 & & & $1.024(0.435,2.407)$ & 0.957 \\
\hline Widowed & 37 & & & $2.077(1.011,4.268)$ & 0.047 \\
\hline Metastatic & & 0.397 & 0.941 & & 0.943 \\
\hline Married & 13 & & & Reference & \\
\hline Single & 20 & & & - & 0.798 \\
\hline Divorced/separated & 9 & & & - & 0.613 \\
\hline Widowed & 16.5 & & & - & 0.831 \\
\hline
\end{tabular}

TABLE 7: Univariate and multivariate analysis for evaluating the influence of marital status on CCS according to SEER stage.

\begin{tabular}{|c|c|c|c|c|c|}
\hline \multirow{2}{*}{ Variables } & \multirow{2}{*}{ Median OS (month) } & \multicolumn{2}{|c|}{ Univariate analysis } & \multicolumn{2}{|c|}{ Multivariate analysis } \\
\hline & & Log-rank $\chi^{2}$ & $P$ value & HR (95\% CI) & $P$ value \\
\hline Localized & & 57.760 & $<0.001$ & & $<0.001$ \\
\hline Married & 46 & & & Reference & \\
\hline Single & 43 & & & $1.051(0.864,1.278)$ & 0.620 \\
\hline Divorced/separated & 44 & & & $1.260(1.010,1.573)$ & 0.041 \\
\hline Widowed & 43 & & & $1.953(1.633,2.336)$ & $<0.001$ \\
\hline Regional & & 22.116 & $<0.001$ & & $<0.001$ \\
\hline Married & 54 & & & Reference & \\
\hline Single & 60 & & & $0.751(0.478,1.179)$ & 0.213 \\
\hline Divorced/separated & 46.5 & & & $0.875(0.513,1.494)$ & 0.625 \\
\hline Widowed & 31 & & & $2.161(1.483,3.151)$ & $<0.001$ \\
\hline Metastatic & & 0.500 & 0.919 & & 0.924 \\
\hline Married & 11.5 & & & Reference & \\
\hline Single & 19 & & & - & 0.877 \\
\hline Divorced/separated & 9 & & & - & 0.526 \\
\hline Widowed & 15 & & & - & 0.880 \\
\hline
\end{tabular}



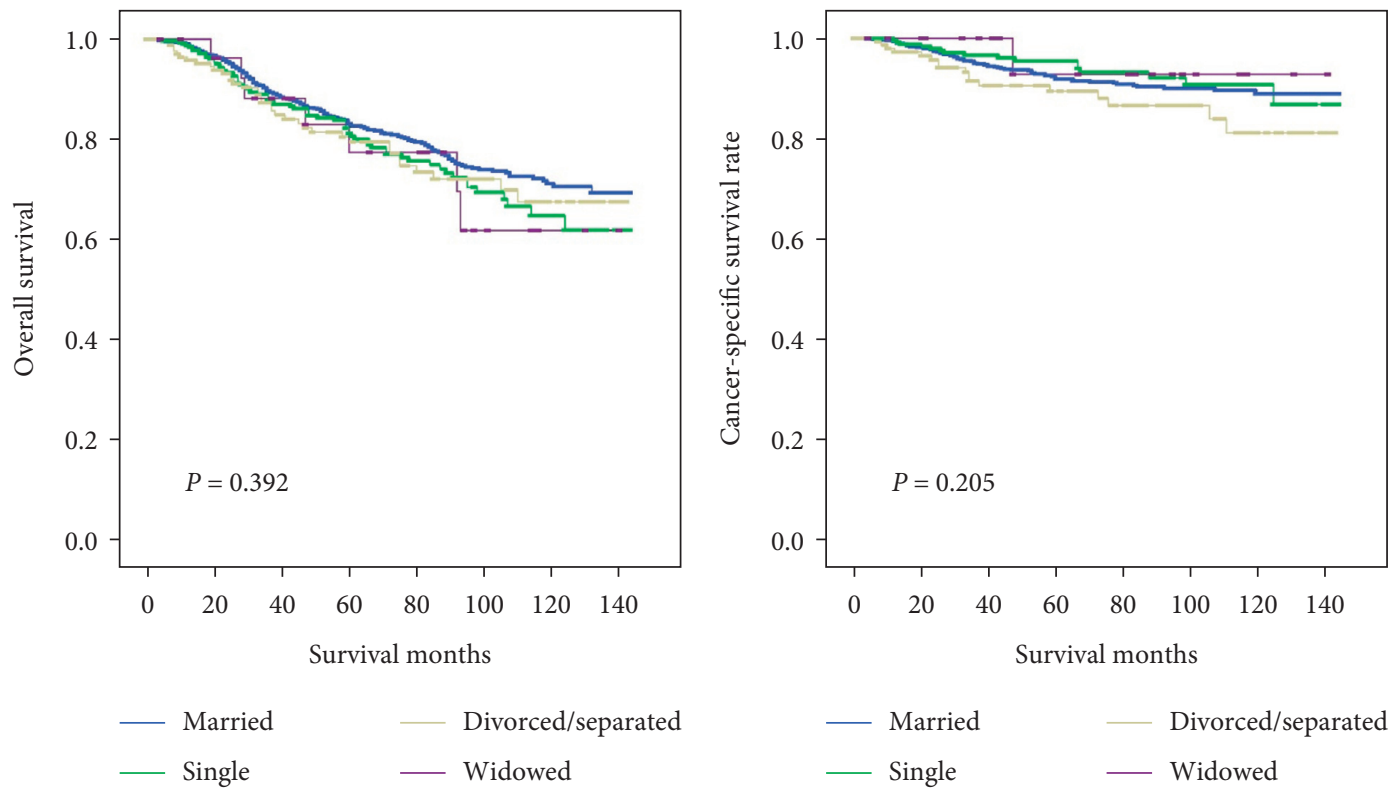

(a)

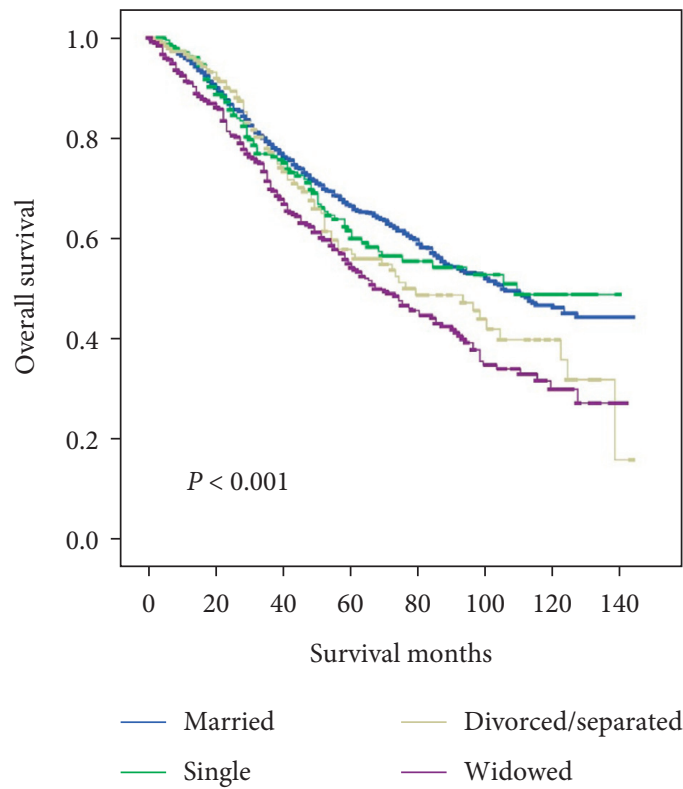

(c)

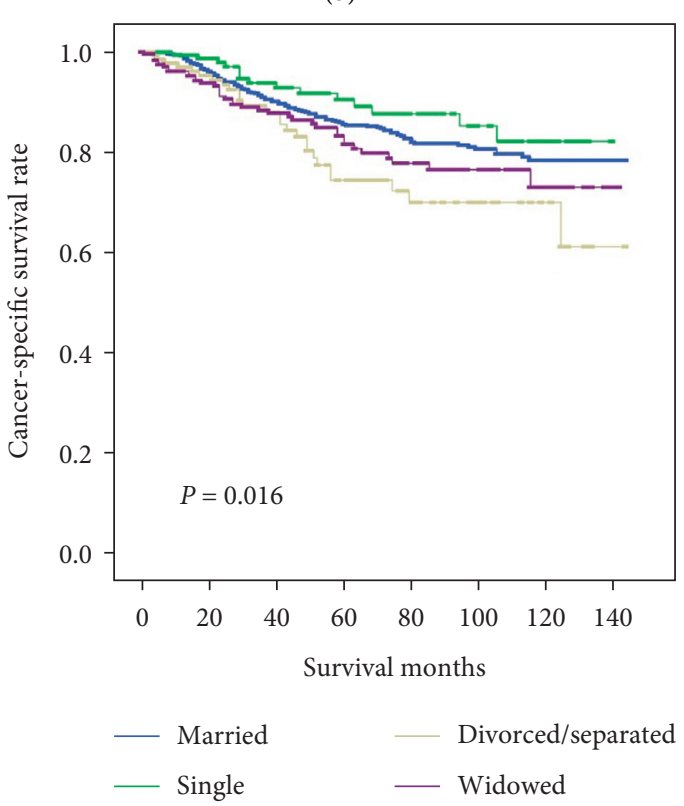

(d)

FigURE 5: Kaplan-Meier comparison of OS and CSS among patients stratified by age at diagnosis. (a, b) Patients lower than 60 years old and (c, d) patients older than 60 years old.

TABLE 8: Multivariate analysis for evaluating the influence of marital status on OS according to age.

\begin{tabular}{|c|c|c|c|c|c|}
\hline \multirow{2}{*}{ Variables } & \multirow{2}{*}{ Median OS (month) } & \multicolumn{2}{|c|}{ Univariate analysis } & \multicolumn{2}{|c|}{ Multivariate analysis } \\
\hline & & Log-rank $\chi^{2}$ & $P$ value & $\operatorname{HR}(95 \% \mathrm{CI})$ & $P$ value \\
\hline$<60$ & 54 & 2.998 & 0.392 & & 0.395 \\
\hline Married & & & & Reference & \\
\hline Single & & & & - & 0.158 \\
\hline Divorced/separated & & & & - & 0.283 \\
\hline Widowed & & & & - & 0.467 \\
\hline$\geq 60$ & 40 & 25.320 & $<0.001$ & & $<0.001$ \\
\hline Married & & & & Reference & \\
\hline Single & & & & $1.060(0.836,1.344)$ & 0.628 \\
\hline Divorced/separated & & & & $1.248(0.978,1.593)$ & 0.076 \\
\hline Widowed & & & & $1.516(1.282,1.791)$ & $<0.001$ \\
\hline
\end{tabular}


TABLE 9: Multivariate analysis for evaluating the influence of marital status on CSS according to age.

\begin{tabular}{|c|c|c|c|c|c|}
\hline \multirow{2}{*}{ Variables } & \multirow{2}{*}{ Median CSS (month) } & \multicolumn{2}{|c|}{ Univariate analysis } & \multicolumn{2}{|c|}{ Multivariate analysis } \\
\hline & & Log-rank $\chi^{2}$ & $P$ value & HR $(95 \%$ CI $)$ & $P$ value \\
\hline$<60$ & 59 & 4.585 & 0.205 & & 0.215 \\
\hline Married & & & & Reference & \\
\hline Single & & & & - & 0.468 \\
\hline Divorced/separated & & & & - & 0.082 \\
\hline Widowed & & & & - & 0.606 \\
\hline$\geq 60$ & 46 & 10.296 & 0.016 & & 0.021 \\
\hline Married & & & & Reference & \\
\hline Single & & & & $0.715(0.420,1.219)$ & 0.218 \\
\hline Divorced/separated & & & & $1.673(1.100,2.543)$ & 0.016 \\
\hline Widowed & & & & $1.333(0.934,1.901)$ & 0.113 \\
\hline
\end{tabular}

representative as global populations. Moreover, other important data, such as body mass, diet, and social status, were not included in this study. Therefore, we need to analyze the patients in different countries such as China or other countries and enlarge the samples, which might be more reliable.

\section{Conclusion}

In conclusion, our study indicated that marital status was proved to be an independent prognostic value for survival in UM patients. Better prognosis and therapeutic outcomes were observed in married individuals compared with widowed ones. Greater risks for OS and CSS were observed in unmarried patients, in particular, widowed when compared with married individuals. Hence, we need to provide more physical and psychological care for widowed patients.

\section{Data Availability}

The data used to support the findings of this study are included within the article.

\section{Disclosure}

The views expressed in the submitted article are the authors' own and not an official position of the institution or funder.

\section{Conflicts of Interest}

The authors declare no conflicts of interest related to this study.

\section{Authors' Contributions}

Wenting Cai and Jiaqi Fan contributed equally to this work.

\section{Acknowledgments}

This work was supported by the Fundamental Research Funds for the Central Universities (no. 22120180509) and Natural Science Foundation of Shanghai (no. 19ZR1439500).

\section{References}

[1] M. Vasalaki, I. D. Fabian, M. A. Reddy, V. M. L. Cohen, and M. S. Sagoo, "Ocular oncology: advances in retinoblastoma, uveal melanoma and conjunctival melanoma," British Medical Bulletin, vol. 121, no. 1, pp. 107-119, 2017.

[2] C. C. McLaughlin, X.-C. Wu, A. Jemal, H. J. Martin, L. M. Roche, and V. W. Chen, "Incidence of noncutaneous melanomas in the U.S," Cancer, vol. 103, no. 5, pp. 1000-1007, 2005.

[3] A. D. Singh, M. E. Turell, and A. K. Topham, "Uveal melanoma: trends in incidence, treatment, and survival," Ophthalmology, vol. 118, no. 9, pp. 1881-1885, 2011.

[4] Y. J. Rao, J. Sein, S. Badiyan et al., "Patterns of care and survival outcomes after treatment for uveal melanoma in the post-coms era (2004-2013): a surveillance, epidemiology, and end results analysis," Journal of Contemporary Brachytherapy, vol. 5, no. 5, pp. 453-465, 2017.

[5] B.-S. Jang, J. H. Chang, S. Oh, Y. J. Lim, and I. H. Kim, "Surgery vs. radiotherapy in patients with uveal melanoma," Strahlentherapie und Onkologie, vol. 193, no. 11, pp. 931-942, 2017.

[6] S.-1. Zhang, W.-r. Wang, Z.-j. Liu, and Z.-m. Wang, "Marital status and survival in patients with soft tissue sarcoma: a population-based, propensity-matched study," Cancer Medicine, vol. 8, no. 2, pp. 465-479, 2019.

[7] C. Xu, X. Liu, Y.-P. Chen et al., "Impact of marital status at diagnosis on survival and its change over time between 1973 and 2012 in patients with nasopharyngeal carcinoma: a propensity score-matched analysis," Cancer Medicine, vol. 6, no. 12, pp. 3040-3051, 2017.

[8] J. Robards, M. Evandrou, J. Falkingham, and A. Vlachantoni, "Marital status, health and mortality," Maturitas, vol. 73, no. 4, pp. 295-299, 2012.

[9] R. L. Shi, N. Qu, Z. W. Lu, T. Liao, Y. Gao, and Q. H. Ji, “The impact of marital status at diagnosis on cancer survival in patients with differentiated thyroid cancer," Cancer Medicine, vol. 5, no. 8, pp. 2145-2154, 2016.

[10] A. D. Sweeney, A. E. Glasgow, M. J. Link, E. B. Habermann, and M. L. Carlson, "Influence of marital status on vestibular schwannoma in the United States," Otology \& Neurotology, vol. 37, no. 6, pp. 793-798, 2016.

[11] J.-C. Xie, S. Yang, X.-Y. Liu, and Y.-X. Zhao, "Marital status is associated with survival of patients with astrocytoma," Journal of Clinical Neuroscience, vol. 56, pp. 79-87, 2018.

[12] W. J. Lowery, M. P. Stany, N. T. Phippen et al., "Survival advantage of marriage in uterine cancer patients contrasts poor outcome for widows: a Surveillance, Epidemiology and 
End Results study," Gynecologic Oncology, vol. 136, no. 2, pp. 328-335, 2015.

[13] V. K. Alamanda, Y. Song, and G. E. Holt, "Effect of marital status on treatment and survival of extremity soft tissue sarcoma," Annals of Oncology, vol. 25, no. 3, pp. 725-729, 2014.

[14] A. A. Aizer, M.-H. Chen, E. P. McCarthy et al., "Marital status and survival in patients with cancer," Journal of Clinical Oncology, vol. 31, no. 31, pp. 3869-3876, 2013.

[15] A. E. Fintel, O. Jamy, and M. G. Martin, "Influence of insurance and marital status on outcomes of adolescents and young adults with acute lymphoblastic leukemia," Clinical Lymphoma Myeloma and Leukemia, vol. 15, no. 6, pp. 364$367,2015$.

[16] G. Inverso, B. A. Mahal, A. A. Aizer, R. B. Donoff, N. G. Chau, and R. I. Haddad, "Marital status and head and neck cancer outcomes," Cancer, vol. 121, no. 8, pp. 1273-1278, 2015.

[17] E. W. Schaefer, M. Z. Wilson, D. Goldenberg, H. Mackley, W. Koch, and C. S. Hollenbeak, "Effect of marriage on outcomes for elderly patients with head and neck cancer," Head \& Neck, vol. 37, no. 5, pp. 735-742, 2015.

[18] C. F. Jehn, D. Kühnhardt, A. Bartholomae et al., "Association of IL-6, hypothalamus-pituitary-adrenal axis function, and depression in patients with cancer," Integrative Cancer Therapies, vol. 9, no. 3, pp. 270-275, 2010.

[19] M. Maarouf, C. L. Maarouf, G. Yosipovitch, and V. Y. Shi, "The impact of stress on epidermal barrier function: an evidence-based review," British Journal of Dermatology, vol. 181, no. 6, pp. 1129-1137, 2019.

[20] R. Nowland, S. J. Robinson, B. F. Bradley, V. Summers, and P. Qualter, "Loneliness, HPA stress reactivity and social threat sensitivity: analyzing naturalistic social challenges," Scandinavian Journal of Psychology, vol. 59, no. 5, pp. 540-546, 2018.

[21] M. H. Antoni, S. K. Lutgendorf, S. W. Cole et al., "The influence of bio-behavioural factors on tumour biology: pathways and mechanisms," Nature Reviews Cancer, vol. 6, no. 3, pp. 240-248, 2006.

[22] M. Vodicka, P. Ergang, T. Hrncir et al., "Microbiota affects the expression of genes involved in HPA axis regulation and local metabolism of glucocorticoids in chronic psychosocial stress," Brain, Behavior, and Immunity, vol. 73, pp. 615-624, 2018.

[23] H. Hasselmann, S. Gamradt, A. Taenzer et al., "Pro-inflammatory monocyte phenotype and cell-specific steroid signaling alterations in unmedicated patients with major depressive disorder," Frontiers in Immunology, vol. 9, p. 2693, 2018.

[24] A. Gadek-Michalska, J. Tadeusz, P. Rachwalska, and J. Bugajski, "Cytokines, prostaglandins and nitric oxide in the regulation of stress-response systems," Pharmacological Reports, vol. 65, no. 6, pp. 1655-1662, 2013.

[25] E. M. V. Reiche, S. O. V. Nunes, and H. K. Morimoto, "Stress, depression, the immune system, and cancer," The Lancet Oncology, vol. 5, no. 10, pp. 617-625, 2004.

[26] G. Goldzweig, E. Andritsch, A. Hubert et al., "Psychological distress among male patients and male spouses: what do oncologists need to know?" Annals of Oncology, vol. 21, no. 4, pp. 877-883, 2010.

[27] S. Long, M. Li, S. Ou, and G. Li, "The effect of marital status on glioma patient survival," Medicine, vol. 97, no. 52, p. e13900, 2018.

[28] M. E. Magrin, M. D’Addario, A. Greco et al., "Social support and adherence to treatment in hypertensive patients: a metaanalysis," Annals of Behavioral Medicine, vol. 49, no. 3, pp. 307-318, 2015.
[29] S. L. Gomez, S. Hurley, A. J. Canchola et al., "Effects of marital status and economic resources on survival after cancer: a population-based study," Cancer, vol. 122, no. 10, pp. 1618-1625, 2016.

[30] T. Akinyemiju, J. X. Moore, A. I. Ojesina, J. W. Waterbor, and S. F. Altekruse, "Racial disparities in individual breast cancer outcomes by hormone-receptor subtype, area-level socioeconomic status and healthcare resources," Breast Cancer Research and Treatment, vol. 157, no. 3, pp. 575-586, 2016.

[31] C. Burgess, V. Cornelius, S. Love, J. Graham, M. Richards, and A. Ramirez, "Depression and anxiety in women with early breast cancer: five year observational cohort study," BMJ, vol. 330, no. 7493, p. 702, 2005.

[32] J. S. Goodwin, D. D. Zhang, and G. V. Ostir, "Effect of depression on diagnosis, treatment, and survival of older women with breast cancer," Journal of the American Geriatrics Society, vol. 52, no. 1, pp. 106-111, 2004.

[33] T. J. Williamson, A. Jorge-Miller, T. A. McCannel, T. M. Beran, and A. L. Stanton, "Sociodemographic, medical, and psychosocial factors associated with supportive care needs in adults diagnosed with uveal melanoma," JAMA Ophthalmology, vol. 136, no. 4, pp. 356-363, 2018.

[34] P. N. Butow, M. L. Bell, M. L. Bell et al., "Conquer fear: protocol of a randomised controlled trial of a psychological intervention to reduce fear of cancer recurrence," $B M C$ Cancer, vol. 13, no. 1, p. 201, 2013.

[35] E. H. Boesen, L. Ross, K. Frederiksen et al., "Psychoeducational intervention for patients with cutaneous malignant melanoma: a replication study," Journal of Clinical Oncology, vol. 23, no. 6, pp. 1270-1277, 2005.

[36] N. Rajeshuni, T. Zubair, C. A. Ludwig, D. M. Moshfeghi, and P. Mruthyunjaya, "Evaluation of racial, ethnic, and socioeconomic Associations with treatment and survival in uveal melanoma, 2004-2014," JAMA Ophthalmology, vol. 138, no. 8, pp. $876-884,2020$. 